\title{
El Consulado de comercio de Buenos Aires y sus redes económicas y políticas: las Diputaciones de Potosí y Montevideo, 1795-1812
}

\author{
Javier Kraselsky \\ javierkraselsky@hotmail.com \\ Doctor en Historia \\ Nacional de Tres de Febrero. (Argentina)
}

Recibido: junio de 2015

Aprobado: septiembre de 2015

Resumen: El objetivo de este trabajo es analizar los nexos políticos, económicos e institucionales entre la Corona hispánica y los comerciantes del virreinato del Río de la Plata a través del estudio del consulado de Buenos Aires y sus diputaciones regionales a fines del siglo XVIII y comienzos del XIX. Se abordarán las relaciones complementarias y conflictivas entre la Junta de gobierno del consulado de Buenos Aires y los comerciantes de las diputaciones de Potosí y Montevideo. Se propone analizar el situado del comercio o las recaudaciones realizadas por el conductor de caudales en Potosí con destino a Buenos Aires y las iniciativas de los comerciantes montevideanos de formar su propio consulado hasta su fundación en 1812. Se pretende analizar como a través de las redes consulares es posible comprender las relaciones de poder entre las elites porteña y las del interior del virreinato en momentos de derrumbe de la monarquía y de surgimiento de nuevas entidades estatales.

Pablaras claves: Consulado de Buenos Aires; juntas de comercio; Diputación en Potosí; Diputación en Montevideo; situado de comercio; Río de la Plata

The Consulate of Trade of Buenos Aires and its economic and politic networks: Diputaciones of Potosí and Montevideo (1795-1812)

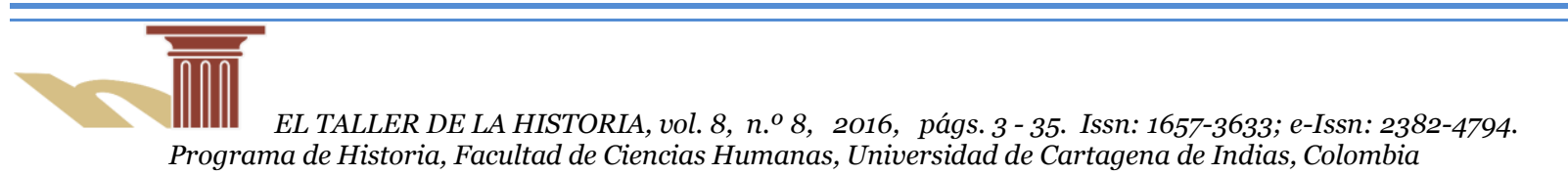




\begin{abstract}
The goal of this work is to analyze the economic, politic and institutional links between the Hispanic Monarchy and the traders in the Viceroyalty of Rio de la Plata. The topic is studying the Consulate of Buenos Aires and the local Diputaciones at the end of the Eighteenth Century and at the beginning of Nineteenth Century. The study points out the relationship between the Junta de Gobierno of the Consulate of Buenos Aires and the traders of the Diputaciones of Potosí and Montevideo. This work proposes to analyze the Situado of Commerce or the income of conductor de caudales (Chief of revenue) from Potosi to Buenos Aires and the Montevidean trader's initiatives to create their own consulate, created in 1821. The study of the consulate network helps to understand the balance of power between the elites porteñas (elite from Buenos Aires) and the viceroyal elite at the time of Hispanic Monarchy crash and the rising of a new country stablishment.
\end{abstract}

Key words: Consulate of Buenos Aires, Juntas of Commerce; Diputación of Potosí; Diputación of Montevideo; Situado of Commerce; Río de la Plata

\title{
Introducción
}

El objeto de este trabajo es analizar las relaciones complementarias y conflictivas entre la Junta de Gobierno del Consulado de comercio de Buenos Aires y dos de sus diputaciones, Potosí y Montevideo, desde la creación de estas últimas en 1795 hasta su supresión en la primera década del siglo XIX. Se analizará la dimensión política e institucional del período de derrumbe de las estructuras monárquicas y la formación de nuevas entidades soberanas que concluirán en los Estados nacionales de mediados del siglo XIX.

El consulado de comercio de Buenos Aires se creó en 1794 y funcionó hasta $1821^{1}$. Sus funciones fueron tanto judiciales como corporativas, como tribunal mercantil debía resolver los conflictos entre pares y como cuerpo representaba a los comerciantes ante las autoridades monárquicas. En este sentido, las elites dirigentes buscaban lograr la

\footnotetext{
${ }^{1}$ El consulado fue la institucionalización de un lento desarrollo de la corporación mercantil local en el cual los comerciantes convocaban a juntas de Comercio. Dichas Juntas habían sido un recurso corporativo por el cual los comerciantes defendían sus intereses. Se originaron en 1748 y se consolidaron en 1779 mediante una estructura política que comprendía apoderados permanentes elegidos por sus pares. El Reglamento de Libre Comercio de 1778 autorizó la creación de consulados, pero este recién se fundó en 1794. Véase Javier Kraselsky, "Las estrategias de los actores del Río de la Plata: las Juntas y el Consulado de comercio de Buenos Aires a fines del Antiguo Régimen (1748-1809)", Tesis de Doctorado, Universidad Nacional de La Plata, inédita
} 
obtención de beneficios colectivos en contraprestación a la recaudación de los ingresos de toda la comunidad mercantil². El Consulado de Buenos Aires poseía una red de diputaciones que cumplían las funciones de consulados en cada una de las regiones del virreinato. 3 Las Diputaciones eran instituciones dependientes de los consulados creadas en algunas ciudades que debido a su crecimiento económico regional y al impulso de las elites necesitaban una mayor agilidad en el uso de la justicia. Dichas diputaciones conformaban también cuerpos de defensa de los intereses comunes y que como expresión de las elites regionales muchas veces culminaron rivalizando con sus antiguos núcleos consulares. ${ }^{4}$ Las diputaciones no fueron analizadas en profundidad. ${ }^{5}$ No obstante ello,

${ }^{2}$ En mi tesis de doctorado analicé las relaciones entre la corona y los cuerpos locales a través del concepto de Centralización corporativa. Este se refiere -desde la perspectiva rioplatense- al sistema de relaciones de poder entre la Corona y los actores americanos. Estos, en el siglo XVIII, se conformaron como cuerpos con intereses similares que desarrollaron estrategias comunes para alcanzar sus objetivos. Esta relación de poder de la Corona sobre los cuerpos locales, lejos de ser absoluta presentaba mecanismos de negociación. Dichos mecanismos le otorgaban a la Corona la conservación de los territorios y los recursos monetarios a cambio del reconocimiento como elite local y de privilegios corporativos. Véase J. Kraselsky, "Las estrategias de los actores...”.

3 El articulo X de la cedula de Erección del Consulado, establece las diputaciones de Ellas fueron Catamarca, Cochabamba, Córdoba, Corrientes, Jujuy, La Paz, La Plata, Mendoza, Montevideo, Oruro, Asunción del Paraguay, Potosí, Salta, Santa Fe, Santiago del Estero, San Juan, Tucumán, Villa Real de Concepción. Documentos para la Historia Argentina, Buenos Aires: Facultad de Filosofía y Letras. Instituto de Investigaciones Históricas (DHA),tomo VII, 1936, p. 55.

4 Yovana Celaya Nández, "Los Diputados de la Junta de comercio de Puebla: estrategias de negociación y representación de intereses en el siglo XVIII", Congreso latinoamericano de Historia Económica CLADHE III-XXIII, Universidad Nacional del Comahue, San Carlos de Bariloche (República Argentina), 2012; Oscar Cruz Barney, El régimen jurídico de los consulados de comercio indianos: 1784-1795, México, Instituto de Investigaciones Jurídicas de la Universidad Nacional Autónoma de México, 2001; del mismo autor "Las diputaciones foráneas del consulado de México: 1807 y 1816" en Ibarra Antonio y Guillermina del Valle Pavón (coord.), Redes sociales e Instituciones comerciales en el imperio español, siglos XVIII a XIX, México, Instituto Mora, 2007, pp. 295-325; Cristina Mazzeo, Gremios mercantiles en las guerras de la independencia. Perú y México en la transición de la colonia a la República, 1740-1840, Lima, Instituto de Estudios Peruanos/Banco Central de Reserva del Perú, 2012.

5 Para la Diputación del consulado de Buenos Aires en Potosí, véase Germán Tjarks, "Potosí y los situados del comercio", Boletín del Instituto Ravignani, año IV, tomo IV nº8, 1960, pp. 46-82; Eduardo Saguier, "La conducción de los caudales de oro y de plata como mecanismo de corrupción. El caso del situado asignado a Buenos Aires por las Cajas Reales de Potosí en el Siglo XVIII", Historia, vol. 24, 1989, pp. 287317; Javier Kraselsky, "El consulado de comercio de Buenos Aires y sus redes locales. El caso de la Diputación de Potosí a fines del siglo XVIII y comienzos del XIX", Congreso Latinoamericano de Historia Económica (CLADHE IV), Universidad de Bogotá Jorge Tadeo Lozano. Bogotá, Colombia, 23-25 de julio de 2014. Para la Diputación de Montevideo fue analizada por Aurora, Capillas de Castellanos, Historia del Consulado de Comercio de Montevideo (1795-1815), Montevideo, Museo Histórico Nacional, Tomo XXII, 1962; Germán Tjarks, El Consulado de Buenos Aires y sus proyecciones en la Historia del Río de 
contamos con trabajos que han estudiado la del consulado de Lima en Buenos Aires que nos pueden servir como ejemplo. ${ }^{6}$

Mediante este trabajo pretendo demostrar que las elites regionales que dominaban las diputaciones del Consulado de Buenos Aires se habrían conformado en juntas de comercio en las que, como las juntas porteñas anteriores a la creación del consulado, los comerciantes defendían sus intereses corporativos y privilegios reclamando medidas a las autoridades para su propia conveniencia a cambio de lo cual debían extraer recursos de la comunidad local. Estas elites regionales habrían convocado a Junta general de comerciantes, ámbito en el cual los actores elaboraban estrategias para proteger sus ventajas corporativas frente a la Corona y a la elite porteña. Estas elites habrían tenido la capacidad de imponer al resto de la comunidad gravámenes comerciales en beneficio propio y del Estado monárquico.

Los comerciantes de Buenos Aires, mediante su Consulado, habrían consolidado su hegemonía política e institucional regional afianzando las redes extendidas hacia el interior del espacio virreinal y hacia la banda oriental del Río. Esto habría generado tensiones y competencias con los comerciantes de estas regiones por el control de los mercados, provocando, como en el caso de Montevideo, la formación de su propio Consulado en 1812. Las dos regiones fueron centros productivos y mercantiles donde se crearon diputaciones subordinadas al poder político de la Junta de Gobierno de Buenos Aires, pero que en las prácticas económicas distaba de ser así.

la Plata. Buenos Aires, Instituto de Historia Argentina “Doctor Emilio Ravignani”, 1962, pp. 80-93. Actualmente el trabajo de Luis Aguirre, "Los consulados de comerciantes en la Independencia de Hispanoamérica, el caso del Consulado de Montevideo: 1794-1838", México, Tesis para obtener el grado de Maestro en Economía, UNAM, 2014, aunque se refiere al Consulado de Montevideo, arroja luz sobre sus antecedentes.

${ }^{6}$ El problema del Diputado de Comercio de Buenos Aires fue tratado por primera vez por Enrique, Barba Don Pedro de Cevallos, Madrid, Instituto de Cooperación Iberoamericana, -1937- 1988, pp. 93-100; José María Mariluz Urquijo, "El Diputado del Consulado de Lima en Buenos Aires", Academia Nacional de la Historia. Memoria del Cuarto Congreso Venezolano de Historia, tomo II, Caracas, 1983, pp. 331-343; Zacarías Moutoukias, "Las formas complejas de la Acción política: Justicia corporativa, faccionalismo y redes sociales (Buenos Aires, 1750-1760)", Jahrbuch für Geschichte Lateinamerikas, Colonia, pp. 69-102 luego esta temática fue retomada en mi tesis de doctorado, J. Kraselsky, "Las estrategias de los actores..." pp. 91-107. 


\section{El Diputado de Comercio del Consulado de Lima en Buenos Aires}

Antes de crearse el Consulado de Buenos Aires, la futura capital del virreinato del Río de la Plata fue sede de una Diputación del Consulado de Lima, generándose un conflicto de competencias jurisdiccionales sobre la capacidad de nombrar a este Diputado.7 La petición de tal Diputación fue realizada por el Gobernador de Buenos Aires Joseph Andonaegui quien envió al Virrey Conde de Superunda, una carta expresando la necesidad de un juez de comercio para resolver los conflictos suscitados en el interior de ese gremio. ${ }^{8}$ Hasta ese momento sólo se habían erigido Diputaciones en Potosí y en Santiago de Chile que funcionaban como instancia jurídica local. La diferencia esencial entre estas tres Diputaciones era que la establecida en Buenos Aires no era elegida por los comerciantes locales como en las otras dos jurisdicciones, sino que era establecida directamente desde Lima.

En 1753 para Buenos Aires, y desde el Consulado Limeño designaron como Diputado y sustituto a Antonio de Larrazabal y Juan Francisco Basurco respectivamente. 9 Esta Diputación no tendría, según lo dispuesto, una periodicidad definida, sino que sería "por el tiempo que fuere, de la voluntad de este tribunal."10 Esto, sumado a los conflictos jurisdiccionales entre las competencias de magistrados en las instituciones, fueron los rasgos salientes de su actividad hasta su disolución en 1756. Los comerciantes residentes en Buenos Aires, que desde 1748 promovían Juntas de comercio, se aliaron momentáneamente a los vecinos en el cabildo de Buenos Aires oponiéndose a la autoridad del Juez y Diputado ${ }^{11}$. Este carecía de legitimidad al no haber sido designado por los actores locales.

Ante esto, el Virrey de Perú, enunció que sería un cargo electivo como en otras regiones. ${ }^{12}$ Así, las autoridades del Río de la Plata convocaron a los comerciantes para

7 E. Barba Don Pedro de Cevallos, pp. 93-100; y J. M. Mariluz Urquijo, “El Diputado del Consulado”, pp. 331-343; y por Z. Moutoukias, "Las formas complejas”, pp. 69-102.

8 AGN IX 39-7-3, expte 4.

9 Archivo General de La Nación de la Republica Argentina (AGN) IX 39-7-3, expte 4 f ${ }^{\circ} 1$.

${ }^{10}$ AGN IX 39-7-3, expte 4, fo 7 vta.

${ }^{11}$ AECBA: Archivo General de la Nación, Acuerdos del Extinguido Cabildo de Buenos Aires. Buenos Aires, República Argentina (AECBA), Serie III, t. I pp. 565-566 y AGN, IX 39-7-3, expte. 4, fo 19, 49.

${ }^{12}$ J. M. Mariluz Urquijo, “El Diputado del Consulado de Lima en Buenos Aires”, p. 339. 
que reunidos en Junta eligieran los electores para designar el próximo Diputado de Comercio. ${ }^{13}$ En este contexto asumió como Gobernador de Buenos Aires Pedro de Cevallos, quien abolió la Diputación estableciendo el regreso a la situación anterior, es decir el establecimiento de la justicia ordinaria para resolver cuestiones comerciales. No se insistirá más con esta institución. No obstante ello, el celo de Lima sobre la cuenca del Plata se hará manifiesto por intermedio de Diputaciones irregulares y asignadas para abordar problemas específicos. ${ }^{14} \mathrm{El}$ estudio de las diputaciones del consulado de Buenos Aires quizás pueda arrojar luz en la problemática de la disgregación espacial del Virreinato y la generación de estados autónomos una vez caída la monarquía hispánica.

\section{2- La Diputación de la Villa Imperial de Potosí}

2-a) Creación de la Diputación, las juntas de comercio y funciones de sus Diputados

La Villa Imperial de Potosí, como es sabido, se caracterizaba por su abundancia de metales, producción que seguía en gran medida las rutas hacia el puerto de Buenos Aires. ${ }^{15}$ En 1736 era una Diputación del consulado de Lima, su Virrey, marques de Villa García sancionó su ordenanza constitutiva. Como dijimos más arriba, la diputación de Lima en

\footnotetext{
13 Pero aquí, se inició la cuestión de establecer quiénes podían participar de esa Junta generándose las rivalidades internas dentro de los comerciantes, residentes o españoles y vecinos de Buenos Aires. AECBA, Serie III, t. II, p. 16

14 Fueron ejemplo de ello, el aumento de los derechos de exportación de los metales a favor de Consulado de Lima en que se designó Diputado por Buenos Aires en 1777/1778 primero a Bernardo Sancho Larrea y Eugenio Lerdo de Texada, y posteriormente en 1784 a Tomas Sáenz de la Peña. AGN, IX 30-9-4, expte. 6; y AGN, IX 4-7-3, expte. 3.

15 Véase por ejemplo Carlos Sempat Assadourian, El Sistema de la Economía Colonial. El mercado interior, regiones y espacio económico, México, Nueva Imagen, 1983; Z. Moutoukias, Contrabando y control colonial en el siglo XVII, Buenos Aires, Centro Editor de América Latina, 1988 pp. 15-69; María Alejandra Irigoin y Roberto Schmit, (Ed.) La desintegración de la economía colonial, Editorial Biblos, Buenos Aires, 2003; C. S. Assadourian y S. Palomeque, "Los circuitos mercantiles del "interior argentino" y sus transformaciones durante la Guerra de la Independencia (1810-1825)" en Susana Bandieri (comp) $L a$ historia económica y los procesos de independencia en la América hispana, Buenos Aires, Prometeo Libros; Viviana Conti y Gabriela Sica, "Arrieros andinos de la Colonia a la Independencia. El negocio de la arriería en Jujuy” Nuevos Mundos Mundos Nuevos, Paris, Año, 2011 p. 1 - 19
} 
Potosí era electiva, en 1748, se citó a los "mercaderes, que actualmente se hallen en Potosí o sus vecinos que sean españoles, y no extranjeros, (...) ni mestizos ni mulatos y que tuvieren tienda publica" para que eligieran a un Diputado de comercio ${ }^{16}$.

En 1776, se crea el Virreinato del Río de la Plata con capital en Buenos Aires, y desde allí, el espacio Atlántico tomó preeminencia institucional anunciando la configuración de la economía del siglo $\mathrm{XIX}^{17}$. Como consecuencia de esta división territorial, la villa real de Potosí, pasó a integrar el nuevo Virreinato y algunos años después se constituyó la diputación del Consulado de Buenos Aires ${ }^{18}$. Las funciones de dicha diputación eran atender y resolver los "muchos y graves los pleitos del comercio" conflictos que en Potosí tenían la particularidad de suscitarse "por la multitud de negociantes y mercaderes que ha atraído la riqueza de los minerales" 19.

Los comerciantes residentes en Potosí intentaron utilizar, desde 1795, la Ordenanza del consulado de Lima como marco institucional para resolver los conflictos. Sin embargo el síndico del consulado porteño, Cristóbal de Aguirre observaba que ellas carecían de validez y que esa región, como todas las demás del Virreinato, debía seguir las disposiciones de la Real Cédula de Erección del consulado de Buenos Aires ${ }^{20}$. Esto lo percibimos como un elemento de conflicto entre los comerciantes residentes en Potosí y la Junta del Gobierno del Consulado porteño. El gremio de comerciantes de Potosí, como el de Buenos Aires, ya existía y con él también la convocatoria a Juntas. ${ }^{21}$

\footnotetext{
${ }^{16}$ AGN sala IX 4-6-12 fo 12.

17 Buenos Aires, desde el siglo XVII poseía una creciente comunidad mercantil, aumentando su importancia económica y mercantil desde las primeras décadas del siglo XVIII. Véase Z. Moutoukias, Contrabando y control colonial... y Fernando Jumar, Le commerce atlantique au Río de la Plata, 1680-1778, Lille: Presses Universitaires du Septentrión, 2 vols, 2002; del mismo autor "La Región Río de la Plata y su complejo durante el Antiguo Régimen”, en Raúl Fradkin (dir.), Historia de la Provincia de Buenos Aires. De la conquista a la crisis de 1820, Buenos Aires, Editorial Edhasa, pp. 123-157.

18 El 26 de julio de 1794, mediante un escrito del Gobernador Intendente Francisco de Paula Sanz se formaba la Diputación de consulado de Buenos Aires manifestando que se ofrecía a "propender en cuanto este de mi parte, y con la mayor eficacia aque tengan este distrito de mi mando." AGN sala IX 46-12 fo 3

19 AGN sala IX 4-6-12 fo 11

20 AGN, sala IX 4-4-7 fo 233.

${ }^{21}$ En 1804, un comerciante local, Francisco de Linares señala "desde el año 1792 antes de la creación de este consulado, fui incorporado al gremio de comercio" luego de la creación del consulado, "fui citado en esta villa por el escribano de su Diputación a todas las juntas de comercio que se han celebrado hasta aquí". AGN sala IX 4-6-12, fo 500.
} 
Los primeros Diputados fueron nombrados por el virrey Nicolás de Arredondo a partir de una lista de candidatos elevada por los gobernadores, intendentes y demás autoridades de las cuales no habrían sido ajenas las juntas de comercio locales. La tarea del primer Diputado y Juez de comercio se encomendó el 24 de noviembre de 1794 a Indalecio González de Socasa, ${ }^{22}$ iniciando la Diputación el 26 de enero de 1795. ${ }^{23}$ Desde la primera reunión comenzaron a manifestarse el choque de intereses de los comerciantes residentes en Potosí y los de la Junta de gobierno instalada en Buenos Aires. Estos intereses estaban vinculados al control político y a la visibilidad como interlocutores del Rey.

En este sentido, el nombrado Diputado cita el 5 de enero de 1795 a "todos los individuos del comercio de esta villa” para intentar designar a un asesor letrado para resolver los conflictos de los particulares. De este modo, los comerciantes residentes en Potosí, resuelven dotar a José María de Sara "con la cantidad de 400 pesos" como de un portero y demás funcionarios. Todo esto no fue bien visto por la Junta de Gobierno del Consulado y su síndico Cristóbal de Aguirre, rechazó la iniciativa 24.

En 1796 es designado como Diputado del consulado de comercio en Potosí Manuel Fernández ${ }^{25}$. Este comenzó gestionando la liberación de derechos en las mercaderías que iban desde España "en derechura" a la villa de Potosí. La Junta de gobierno del consulado aceptó que "no se les formará en esa real aduana el avalúo arbitrario que sucede, de que resulta un perjuicio notable a este comercio" 26 , con lo que el nuevo Diputado contaba con una ventaja para los comerciantes. Pero el apoyo de los comerciantes agrupados en Juntas, pronto se vuelve más difuso con el inicio de los conflictos por la recaudación de caudales como ya veremos. Como sucederá en Montevideo, los diputados son designados hasta la primera década del siglo XIX.

Las funciones de los diputados eran judiciales y de fomento al comercio y la producción. Así, una de las funciones del Diputado era "promover los intereses del publico"

\footnotetext{
22 AGN IX 4-6-12, fo 35 .

23 Esther Aillón Soria, Vida, pasión y negocios: el propietario de la viña San Pedro Mártir, Indalecio González de Socasa (1755-1820), Sucre: Fundación Cultural del Banco Central de Bolivia; Archivo y Biblioteca Nacionales de Bolivia. 2009.

24 AGN, sala IX 4-4-7 fo 233 , fo 276.

25 El 26 de agosto de 1796, Actas: Archivo General de la Nación. Consulado de Buenos Aires. Antecedentes-Actas-Documentos. Buenos Aires: Kraft, 1936 (Consulado), tomo II, p. 160.

${ }^{26}$ Consulado, tomo II, p. 440
} 
para ello debía construir caminos y puentes, limpiar las lagunas, etc. En particular los de la entrada a la villa, donde los Diputados reclamaban utilizar "los propios cuantiosos que tiene esta Republica” 27.

2-b) Tensiones y conflictos: la conducción de los caudales o el situado de comercio de Potosí

El punto de discordia más importante y que estructura las relaciones entre la elite mercantil en Potosí y la Junta de Gobierno del consulado fue el denominado situado de comercio o la conducción de los caudales del Alto Perú hacia Buenos Aires. ${ }^{28}$ Este estaba compuesto por la cantidad de dinero o las encomiendas que los comerciantes entregaban a un recaudador determinado. Los situados del comercio se recaudaban entre los comerciantes residentes en Potosí que se conducían a Buenos Aires para que los comisionistas pudieran utilizarlos adquiriendo productos de la península o para pagar sus deudas. 29

Antes de la creación de la Diputación que comenzó a regular dichos situados, el comercio entre Buenos Aires y Potosí no estuvo circunscripto a un recaudador particular sino que estos conductores eran los comerciantes que se internaban desde el Atlántico al Perú. Ello habría generado competencias y rivalidades entre los comerciantes por su traslado. La falta de regulación de la corporación mercantil de Potosí, volvió necesaria una reforma que promoviera la regularidad de los situados..$^{30}$ Para ello, los comerciantes de Potosí convocaron a junta para tratar el tema y promover una solución ${ }^{31}$.

Así es que se convoca a una junta el 9 de enero de 1795 en la que, 40 individuos impulsan el Reglamento de Situadistas ${ }^{32}$. Por dicho Reglamento, se promovía que los propios comerciantes convocados en Juntas Generales de comercio, tuvieran que nombrar a personas que conjuntamente con el diputado designaran a los conductores de caudales para Buenos Aires. La función del situadista consistía en recaudar y conducir

27 AGN IX 4-6-12 fo 512; 552.

${ }^{28}$ J. Kraselsky, "El consulado de comercio de Buenos Aires....".

29 G. Tjarks, El Consulado de Buenos Aires ... p. 813, y "Potosí y los situados del comercio", p. 47.

30 AGN sala IX 4-7-7, exp. 6.

${ }^{31}$ AGN sala IX, 4-6-12.

$3^{2}$ AGN sala IX, 4-6-12, fo 3 . 
los caudales de toda la carrera y entregarlos a los comisionistas en Buenos Aires que los proveían de artículos europeos, responsabilizándose de cualquier pérdida o percance que pueda llegar a tener en su viaje. Por esta tarea, recibían como pago un porcentaje del envío que variaba según las distancias.

El Reglamento de Situadistas buscaba reducir la vulnerabilidad de los comerciantes a las defraudaciones, a las estafas y a las demoras en la partida de Potosí de sus caudales con destino a Buenos Aires. El Reglamento tenía 17 artículos que tratan sobre cómo y cuándo debía establecerse el transporte de los caudales del comercio y quienes estaban en condiciones de ser designados situadistas. Ellos debían ser designados por seis electores elegidos en junta general de comercio y debían ser del comercio local33. Dichos situadistas tenían que efectuar una fianza de doce mil pesos. El situado, según el Reglamento, salía desde Potosí en dirección a Buenos Aires con la asiduidad de dos meses y la duración del viaje se estimaba en 80 a 90 días, estableciéndose que el situadista llevara los registros en un libro o cuaderno donde dejara asentado los caudales que llevaba y que demostrara el valor, en oro, plata, alhajas, encomiendas, etc. 34

El cumplimiento de este Reglamento fue, como era de esperar, conflictivo y sujeto a reclamos constantes de quienes veían afectados sus intereses particulares. Un grupo de comerciantes se oponía a que los situadistas sean "solo" del comercio de Potosí. Primero porque los comerciantes residentes en otros lugares como Salta, Jujuy y La Paz mediante juntas y oficios reclamaban poder participar en la conducción de caudales35. Segundo por los reclamos de los troperos o los que prestaban los bueyes necesarios para poder llegar a destino. Según el Reglamento ellos serían de Potosí, con lo cual, todos los dedicados a criar y brindar tropas que no eran de la villa, quedaban al margen de tal monopolio. ${ }^{6}$

Además, el cumplimento del Reglamento fue objeto de reclamos por los mismos actores que deslegitimaban las designaciones de situadistas. Desde 1795, las elecciones de los electores estuvieron cuestionadas, los recaudadores o situadistas, para la parte

\footnotetext{
33 AGN Sala IX 4-6-12.

34 Para un análisis del Reglamento, véase J. Kraselsky, “El consulado de comercio de Buenos Aires...”.

35 AGN, sala IX 4-7-7

${ }^{36}$ En este sentido se observan oficios Nicolás da Ponte, a nombre de Pablo Soria, vecino de la provincia las Chichas. AGN, sala IX 4-4-7 o los reclamos de los comerciantes al Diputado Antonio González de Ortega, AGN sala IX 4-6-12 fo 420; fo 430-432
} 
demandante, no cumplían todas las calidades especificadas en la Real Cédula37 y señalaban que en ocasiones existieron fraudes ${ }^{3}$. Las rivalidades personales se manifestaban entre las facciones, como por ejemplo entre González de Socasa y Manuel Fernández39. Estos conflictos surgieron cuando Fernández impulsó multas al hermano del primer Diputado. 40

Este conflicto no fue el único. En marzo de 1798, Domingo de Achucardo, designado Diputado de comercio de la Villa mantuvo una disputa con los comerciantes locales por la legitimidad en la designación de los situadistas. Entre ellos, González de Socasa acompañado de Joaquín de Obregón Zevallos, Manuel de Burucua y Juan Bautista de Ituarte, quienes solicitaron la reforma del Reglamento. ${ }^{41} \mathrm{El}$ diputado cargó contra los comerciantes que pretendían cambiar las reglas del juego, enfatizando que de los 41 que habían aprobado el Reglamento, solo 4 hicieron la representación, "que se hace como en nombre de todo este comercio dirigiéndose a embarrar las resoluciones de esta Junta de Gobierno y de esta Diputación"42.

En octubre de 1798, otra junta de comercio, eligió a los electores para designar situadistas para el bienio de 1798-1800. Esto generó un reclamo de otros comerciantes que veían que sus intereses estaban afectados, lo que encontró apoyo en el Diputado. En el oficio elevado por este a la Junta de gobierno de Buenos Aires el 26 de noviembre de dicho año, se denuncia que entre los firmantes se encontraban comerciantes ausentes y que por lo tanto carecía de valor. Según el oficio, ellos han designado a situadistas que "nada interesan en la conducta de los situados, porque nada remiten a los comerciantes

37 En la primera elección de situadistas, el 4 de marzo de 1795, los comerciantes reunidos en junta se quejan porque fue elegido como situadista Juan Bautista Elorroaga quien no era vecino de Potosí. La elección había sido según ellos nula porque la Junta se celebró sin la presencia del escribano. Estas quejas son lideradas por Juan de Ibieta. AGN sala IX 4-6-12 fo 36 . El 31 de diciembre de 1796, reunidos eligen a Pedro Vals como primer situadista para el año 1797, "por especial recomendación del excelentisimo señor virrey" Pedro Melo de Portugal. Este nombramiento se realizó "no obstante ser este individuo versado en la carrera del comercio en Europa" AGN sala IX 4-4-7 fo 93.

${ }_{38}^{8}$ Marcos Beche fue elegido como elector por intervención del "Gobernador intendente de esta villa". AGN sala IX 4-6-12 fo 12

39 El primero, comerciante, militar primer Diputado del comercio de Potosí y el segundo comerciante local ligado a la Junta de Gobierno del consulado de Buenos Aires y reemplazante de aquel en la Diputación en1796. AGN sala IX 4-7-7 fo 72 y ss.

40 AGN, sala IX 4-4-7, fo 101.

${ }^{41}$ AGN, sala IX 31-1-4 exp 5.

42 AGN, sala IX 31-1-4 exp 5, fo 43 
de esa Capital ni a los de Europa".43 El reclamo se basaba en que estos eran comerciantes de "poco giro" y que solo se concentran en el comercio dentro de la villa, por lo tanto no pueden asegurar las encomiendas y el dinero de los comerciantes. La Junta de Gobierno del consulado, se expresa por su secretario Manuel Belgrano, el 30 de julio de 1799 dándole la razón al Diputado.44

Las Juntas de comercio en Potosí se realizaban esencialmente para definir quienes serían los electores que designaban a los recaudadores de comercio que conectaban a los comerciantes de Potosí con los comerciantes exportadores-importadores de Buenos Aires. Estas juntas se convocaron asiduamente incluso luego de que la Junta de Gobierno del consulado determinara la designación del Diputado en 1803. Este mismo año, el síndico del consulado de Buenos Aires Francisco de Escalada, opinaba que la conflictiva relación con los comerciantes de Potosí solo puede resolverse por una medida que disuelva el control regional de la designación de los situadistas o recaudadores del comercio 45 y promovió que se supriman las juntas de comercio ya que motivaban la rivalidad entre facciones. 46

Así, en el seno de la Junta de Gobierno del consulado de Buenos Aires, el 30 de marzo de 1803 se trató sobre la convocatoria asidua de estas reuniones locales. La Junta de Gobierno resolvió que las juntas de comercio en Potosí deberían reducirse "álos puntos qe. tenga abien determinar se traten en ellas, sin que sea licito transgredir esta disposición" es decir que el cuerpo mercantil en Potosí debería convocarse para designar los situadistas y no para resolver otras cuestiones que el Reglamento podía suscitar, todo esto bajo penas pecuniarias. Además resolvió que para su celebración "deberían hacer presente la disposición de esta a los gobernadores", esto es que las reuniones debían contar con la autorización institucional de las autoridades consulares. 47

\footnotetext{
43 En la junta del 2 de octubre se desinaron situadistas a Amadellier, Ortega, Torres. AGN sala IX 4-6-12 fo 413 .

44 AGN, sala IX 4-6-12 fo 416 vta.

45 AGN, sala IX, 4-4-7 fo 227.

46 Francisco de Escalada, sindico del consulado porteño señala que "esta Junta de gobierno no puede mirar con indiferencia una materia en que tanto interesan sus facultades, autoridad, y respetos, en que se versa la justicia, la equidad y la seguridad del comercio en que se trata del fomento arreglado de una considerable parte de sus miembros". AGN sala IX 4-4-7, expte 6 fo 275.
}

47 AGN, sala IX, 29-1-4, fo 39. 
Siguiendo esta premisas Manuel Belgrano, como secretario del consulado señaló que la Junta de Gobierno estableció que podría designar a un situadista de otra región que no sea Potosí y que "prohíbelas elecciones" como hasta ese momento. Con ello, el consulado revocó la aprobación de la sanción del Reglamento y monopolizó la designación del situadista. ${ }^{8}$ Ante esta decisión, la reacción de González de Socasa no se hizo esperar y mediante juntas locales demostró su descontento. 49

No obstante eso, la Junta de Gobierno del consulado designó a Miguel de Solla, Manuel Toribio de Caviales y Carlos Hurtado Mendoza, el primero era vecino de Salta, el segundo era vecino de Chuquisaca y el tercero era hermano de Joaquín Hurtado de Texerina, Juez y Diputado del consulado de comercio en Potosí, como situadistas en 1803. Ante esto los comerciantes residentes en Potosí se reunieron en junta los días 2, 14 y 16 de octubre de 1803 y, liderados por González de Socasa, establecieron su oposición no prestando su apoyo al situadista designado y dejando al descubierto quien poseía el poder real.50

En mayo de 1804, la Junta de Gobierno del consulado, designó a Miguel Cayetano Romero para conducir los caudales del comercio, quien renunció al observar "las partidas de dinero que llevar.” Romero era vecino de la ciudad de Córdoba del Tucumán y debido al costo y a los riesgos, no había conseguido fiadores en el comercio local. ${ }^{51} \mathrm{El}$ Diputado del consulado en Potosí, Joaquín de Texerina señalaba que la renuncia de Romero se debía a que los comerciantes poderosos han influido sobre él, otorgándole un monto inferior al frecuentado en similares circunstancias..$^{52}$ La facción de González de Socasa controlaba la comunidad de comerciantes residentes en Potosí, su figura política y militar lo demostraba. Este caso de las renuncias a la conducción "oficial" de caudales no ha sido el único a pesar de los cual ésta continuará llevándose a cabo hasta 1809, año del último registro del legajo de la diputación del consulado porteño en Potosí en el Archivo General de la Nación de la República Argentina.53

\footnotetext{
48 AGN, sala IX 4-4-7, fo 289 vta.

49 Junta del 14 de octubre de 1803, AGN, IX 4-4-7, exp. 7, fo 2 y ss.

5o AGN, sala IX 4-4-7, exp. 7, fo 6.

${ }^{51}$ AGN sala IX, 4-4-7 exp. 7 f $^{\circ} 52$.

$5^{2}$ Solamente llevara 50.00o. AGN sala IX, 4-4-7 exp. 7 fo 56 .

53 Fueron elegidos por el consulado José María de Larramendi, Ramón Saravia y Josef Moll en 1804 pero que también han renunciado. AGN sala IX, 4-4-7 exp. 7, fo 60-69. Miguel de Anchoriz también fue designado por la Junta de Gobierno y presentó la renuncia en marzo de 1804. AGN sala IX 4-6-12 fo 471 . En
} 
Con ello, si bien la Junta de Gobierno del consulado había reemplazado el Reglamento por la designación de situadistas de diversas regiones de la ruta que unía al Alto Perú con Buenos Aires demostrando tener capacidad institucional, el poder "real" o territorial seguía estando en las juntas locales. La acción política de González de Socasa de deslegitimar a los situadistas del consulado, negándoles ser fiador o influir en que el resto de los poderosos mercaderes se negaran a confiarle los caudales era la continuación de una política corporativa y local. Es decir, que intentaba exitosamente, establecer otros situadistas particulares y reflejar por medio de ellos el poder real de los comerciantes de la Diputación.

Este poder, se manifestó en el oficio del Diputado Joaquín Texada el 27 de junio de 1804 por el que señalaba que debido a las "intrigas" de los comerciantes que se oponen a la designación del recaudador de caudales por la Junta de Gobierno del consulado y a que el situadista designado José Dalmasio Gomes no se hace presente "ni tampoco há avisado si lo ha renunciado o se lo ha pasado a otro", el Diputado otorgó la decisión de nombrar a un situadista al propio González de Socasa. Así el Diputado señalaba que, "[...] no haviendo por ahora otro sugeto con quien reemplazar la falta (a causa delos efugios, e Intrigas de los que se oponen al cumplimiento de las determinaciones de esa Junta de gobierno) habrá de llevar los caudales del comercio el situadista nombrado por don Indalecio Socasa".54

Finalmente, y aparentemente por el silencio de González de Socasa, el 23 de julio de 1804 Joaquín Texerina señalaba en otro oficio que León Francisco de Urtiaga, vecino de Salta, era el reemplazante del mencionado Gómez. El Diputado agregaba que "todos los individuos del comercio conocen las ventajas que reporta el cuerpo por la justificada económica providencia que esa junta superior tomo en el asuntos de situados”. $55 \mathrm{El}$ caso del recaudador de caudales o situadista del comercio revela las tensiones no solo entre los mismos comerciantes residentes en Potosí, sino los conflictos entre un "viejo" espacio económico y mercantil como Potosí y un espacio en ascenso institucional como Buenos Aires.

octubre de 1804 el situadista Manuel Aunsolo renuncia a ser el conductor de los situados. Los problemas para encontrar sus reemplazantes se vuelve a repetir. AGN sala IX 4-6-12 fo 504

54 AGN sala IX 4-6-12 fo 487.

55 AGN, sala IX, 4-6-12 fo 488 . 


\title{
3) La Diputación en Montevideo
}

\author{
3-a) Diputación y Consulado de comercio en Montevideo
}

Desde su fundación, Montevideo había crecido como centro comercial y militar. ${ }^{6} \mathrm{Su}$ puerto era la entrada y salida legal de la zona; desde 1791 tomó preeminencia en el tráfico negrero57 y en 1797 adquirió relevancia con el comercio con buques neutrales 58 . Con anterioridad a la formación del Consulado de Buenos Aires, Montevideo solicitó a la corona la creación de un Consulado.59 La Diputación de Montevideo se creó el 24 de noviembre de 1794. Los Diputados eran nombrados desde Buenos Aires y su designación revela el poco entusiasmo con el aceptaban. ${ }^{60}$ En la Diputación existieron 8 representantes en total, los cuales eran renovados por bienios. ${ }^{61}$

Esta Diputación mantuvo relaciones tensas con la Junta de Gobierno establecida en Buenos Aires. No obstante ello, eran dos polos que se necesitaban mutuamente. Los

${ }^{6}$ Arturo Bentancur, El puerto colonial de Montevideo. Guerras y apertura comercial: tres lustros de crecimiento económico (1791-1806), Universidad de la Republica, Departamento de Publicaciones, 1997, 13-27; Jumar, F. Le commerce atlantique .... Nicolás Biangardi, Expansión territorial, producción ganadera y relaciones de poder en la región Rio de la Plata. Montevideo y Maldonado a fines del siglo XVIII, Tesis de Doctorado, Universidad Nacional de La Plata, 2015, inédita

57 La Real Cedula de 24 de noviembre de 1791 autorizaba a intercambiar esclavos por frutos por el puerto de Montevideo, DHA, tomo VII, pp 3-9.

${ }^{8}$ Hernán A. Silva, El comercio entre España y el Río de la Plata (1778-1810). Madrid: Banco de EspañaServicio de Estudios- estudios de Historia Económica, 1993, n 26, pp. 91-95; A, Betancur, El puerto colonial de Montevideo... p. 32.

59 A. Bentancur, El puerto colonial de Montevideo. Guerras y apertura comercial..., p. 32 observa que los proyectos de formación del consulado en Montevideo aparecen en 1793. El consulado de Montevideo está siendo analizado desde su fundación por Luis Aguirre. Véase del autor "Los consulados de comerciantes en la Independencia de Hispanoamérica, el caso del Consulado de Montevideo: 1794-1838” y "Desinteligencias en los negocios: Redes sociales y circuitos comerciales durante la Cisplatina en Montevideo", Ad Fontes! Vol. 1, No. 1, 2014.

60 El caso de Juan Balbín Vallejos que en 1796 se niega -en principio- a aceptar, ilustra la situación, Consulado, tomo II, pp. 155-156. Otro caso es el de Juan Francisco Martínez que no quiere aceptar por falta de personal y por poseer estancias las cuales debía atender, solicitaba el 9 de julio de 1800 una "casa y amanuense" fo 1 y dice que posee estancias "bastantes distantes de esta plaza [siendo] el principal sostén de su familia”. AGN IX 4-6-7, expte. 10.

${ }^{61}$ A. Capillas de Castellanos, Historia del Consulado de Comercio de Montevideo (1795-1815), p. 6. 
Diputados funcionaban como representantes del Consulado y ejercían en primera instancia la resolución de casos. Además debían contribuir al engrandecimiento de la agricultura y el tráfico ultramarino, a informar sobre los naufragios, a suministrar la fecha de arribo de los barcos, a recaudar donativos para la corona, a recaudar averías, etc. ${ }^{62}$

El 14 de agosto de 1794, el Diputado del Consulado don Bernardo de la Torre, asociado a su asesor doctor don Juan Bautista Aguiar "y de los individuos de este comercio" se reunieron en junta de comercio para analizar las pautas que convienen observar en esta Diputación. ${ }^{63}$ Posteriormente, Bernardo de la Torre, citó a otra junta el 7 de septiembre con el objeto de crear un Reglamento comercial en el cual basarse para administrar la justicia en aquella plaza. El síndico del Consulado de Buenos Aires, Cristóbal de Aguirre descalificó el intento del Diputado observando que esté debía circunscribirse a administrar la justicia mercantil dejando de lado la función "governativa ni directiva del cuerpo de comercio." Los Diputados, según el síndico, carecían de facultades que los autoricen a "mezclarse, a hacer reglamentos, estatutos y ordenanzas". El síndico consideraba que el Diputado "con visible exceso se ha inducido en materias qe no son de su conocimiento" instando a que se abstenga "en lo sucesivo de entrar en el proyecto de iguales reglamentos ...” 64

Esta respuesta del síndico, se radicalizaba aún más con los gastos realizados para refaccionar el lugar físico donde instalar la Diputación. ${ }^{65}$ Bernardo de la Torre, parecía arrogarse facultades en la designación del personal y "el arreglo de sueldos,"66 lo que el sindico del Consulado, Cristóbal de Aguirre, lo desautorizaba a entender. ${ }^{67}$ Los actores de Montevideo se quejaban por falta de fondos y de bienes de consumo necesarios como tinta, plumas, etc. ${ }^{68}$ Este caso se puede comparar a la Diputación en Potosí, como ya vimos, en el cual se manifiesta un control político e institucional de la Junta de Gobierno sobre los espacios del interior del Virreinato.

\footnotetext{
62 A. Capillas de Castellanos, Historia del Consulado de Comercio de Montevideo (1795-1815) p. 31.

63 AGN IX 4-7-4 leg. 3, también véase G. Tjarks, El Consulado de Buenos Aires..., pp. 801-812.

64 AGN, sala IX 4-7-4, exp. 3, fo 12 vta.

${ }^{65}$ AGN sala IX 4-7-4 leg. 3 , fo 18.

${ }^{66}$ AGN sala IX 4-7-4 leg. 3 , fo 18 .

${ }^{67}$ AGN sala IX 4-7-4 leg. 3, fo 21.

68 AGN sala IX 4-7-4 leg. $3, \mathrm{f}^{\mathrm{o}} 30$.
} 
Posteriormente, el 17 de septiembre de 1798, por medio de una junta de comercio de la que participaron 45 miembros, los comerciantes se quejaban por la designación de José Revuelta, cuando a quien querían era a José Milla de Roca. ${ }^{69}$ A través de este reclamo, los miembros de la junta manifiestan el crecimiento de esta plaza y la necesidad de poseer su propio consulado. Para eso, su estrategia es atacar a la Junta de Gobierno del Consulado de Buenos Aires señalando que ésta creía que los vecinos y comerciantes eran "ineptos" para elegir y desempeñar el cargo de la Diputación de esta Cuidad. Los actores de Montevideo decían que en dicha plaza hay un cuerpo respetable de "buenos vecinos, comerciantes, y ascendados" capaces de desempeñar las funciones de un consulado propio.70 $\mathrm{Al}$ igual que en Potosí el control institucional de la Junta de Gobierno se manifestaba en la designación de los Diputados y en el caso potosino también en los recaudadores de los caudales del comercio o situadistas.

En Montevideo subrayan que la Junta de Gobierno de Buenos Aires, siempre se ha "negado a toda justa solicitud de esta Diputación" como por ejemplo los gastos relativos al puerto y muelle ${ }^{71}$. En protesta no reconocen al Diputado José de Revuelta por no cumplir requisitos de residencia "no tiene casa propia, pero tampoco alquilada, pues esta recogido en la de su suegro, ejerciendo su facultad para su subsistencia sin conocerle otro arbitrio" 72 y reclamaban que hasta tanto no se llame a elecciones en que se tenga en cuenta a los individuos "beneméritos, y aptos como hay y abundan en esta ciudad". 73

El 28 de octubre de 1799, los comerciantes y hacendados de Montevideo se reunieron en Junta y solicitaron la creación de su propio Consulado. Ellos pedían al Rey mediante una representación "se digne alzarles la sujeción opresiva, y funesta dependencia del Consulado de Buenos Aires; y concederles la Erección de su Tribunal de Comercio". ${ }^{74}$ Los actores de Montevideo manifestaban su necesidad de autonomía de Bue-

\footnotetext{
69 AGNU, libro 477, fo 14.

70 AGNU, libro 477, fo 14.

${ }^{71}$ AGNU, libro 477, $\mathrm{f}^{\mathrm{o}} 15$

72 AGNU, libro 477, fo 14 vta

73 AGNU, libro 477, fo 16- 16 vta

74 DHA, tomo VII, p.161.
} 
nos Aires basados en la distancia, en las dificultades de la navegación entre los dos puertos, en los hundimientos75 y en la incomodidad de recurrir a la Capital por los pleitos entre comerciantes. ${ }^{76}$ Ellos alegaban como solución la creación de un tribunal en Montevideo ${ }^{77}$. Esta rivalidad ha sido analizada desde una perspectiva nacionalista como un elemento que explicaría la formación de una conciencia política y una identidad que llevaría como un proceso lógico a la formación de dos naciones. En este trabajo, la perspectiva es otra. En ese sentido el concepto de territorio no puede asemejarse a territorio nacional como en la segunda mitad del siglo XIX, sino como territorios de la Monarquía compuesta de los siglos XVII y XVIII ${ }^{8}$. La identidad nacional lejos de ser preexistente a la formación de los Estados de mediados del siglo XIX, es un fenómeno de inicios del siglo XX.

Las juntas no fueron solo convocadas para gestionar su propio consulado o reclamar por las elecciones de sus Diputados, lo fueron también por temas fiscales y de defensa territorial. Estos temas también se manifestaban en Potosí, pero en el caso altoperuano se vinculaban a la recaudación de los caudales que los comerciantes locales enviaban con destino a Buenos Aires. En Montevideo por ejemplo se realizaron Juntas de comercio con el fin de recaudar los préstamos y donativos a la corona para colaborar a financiar los gastos de las guerras. Esta política de intermediación del consulado fue constante, no sólo en el Río de la Plata sino en todas las regiones americanas.79 En otros trabajos hemos planteado la estrecha relación entre la recaudación de los préstamos y donativos con la creación del consulado de Buenos Aires. ${ }^{80}$ La junta de comercio de

$75 \mathrm{El}$ tema de los hundimientos está en permanente discusión a lo largo del período véase Sala IX 4-6-9 f ${ }^{\circ}$ 5, 16. Consulado, tomo II, p. 172.

${ }^{76}$ Consulado, tomo II, p. 162.

77 Consulado, tomo II, p. I64.

78 Véase John Elliott, “A Europe of Composite Monarchies”, Past and Present, 137, 1992, 48-71; Conrad R. y Gallego J. A. (Dirs.), Las monarquías del Antiguo Régimen, ¿̇monarquías compuestas?, Madrid, Editorial Complutense, 1996.

79 Rafael, Torres Sánchez, El precio de la guerra. El Estado fiscal-militar de Carlos III (1779-1783), Marcial Pons. Historia, 2013, pp. 13-129.

8 Javier Kraselsky, "Los comerciantes rioplatenses y sus estrategias de negociación corporativa. Las Juntas de comercio, 1779-1794". Redes sociales e Instituciones consulares en el Imperio Español, siglos XVII a XIX, coordinado por Ibarra A. y Valle Pavón del G., Instituto de Investigaciones Dr. José María Luís Mora y la Facultad de Economía de la Universidad Nacional Autónoma de México, 2007, pp. 249-278; de mismo autor "Las Juntas de comercio y el Consulado de Buenos Aires y sus relaciones con la Corona: los 
Buenos Aires primero y el consulado después, recaudaron 100.000 entre 1793 y 1794 para colaborar con los gastos de la corona en la guerra contra la Francia revolucionaria. Estos fondos se iban a devolver de las averías y demás impuestos comerciales.

En Montevideo los comerciantes y hacendados no estaban de acuerdo con la recaudación de los fondos de la comunidad para financiar el préstamo realizado por Buenos Aires. Esto se refleja en la Junta de comerciantes de Montevideo del 14 de febrero de 1794, reunión que contó, como ya he dicho, con 80 integrantes. Ellos manifiestan que "este comercio es enteramente independiente, e indistinto del dela capital de Buenos Ayres" y que la capital no puede obligarlos ni disponer de sus fondos. ${ }^{81}$ El conjunto otorga poder a Juan Pedro de Aguirre, Juan de Ellauri y Juan Balbín González de Vallejo "de este vecindario y comercio, general para que por sí mismos y en voz y en nombre de todos los concurrentes a esta junta; y representando sus propias personas, derechos y acciones..." 82 promuevan lo conducente a oponerse a tal práctica, lo que era visto como una "imposición" de la Junta de Gobierno.

El 23 de diciembre de 1797, el Diputado Juan de Balbín de Vallejo convoca a otra junta de la que participan 39 miembros del comercio de Montevideo, con el objetivo de continuar la cuestión del donativo. En ella, dan a conocer la opinión del virrey quien establece "que dejaba al arbitrio de los comerciantes de aquella plaza (Montevideo) la voluntad en los ofrecimientos". ${ }^{3}$ A partir de la resolución virreinal, los actores de Montevideo aportan un porcentaje de lo recaudado. El 28 de octubre de 1799, los comerciantes y hacendados de Montevideo se reunieron en Junta y solicitaron la creación de su propio Consulado. Como fundamento mencionaban lo contribuido en el préstamo y donativo de 1793, es decir intentaban hacer valer lo contribuido sacando rédito. En ella mencionan que el monto recaudado "pasa de treinta mil pesos" enfatizando que esperan que con tal suma obtener su propio consulado. ${ }^{84}$ En este sentido se puede comparar con los resultados obtenidos en esa época por los comerciantes de Buenos Aires en la que fueron autorizados a crear el Consulado como contraprestación por lo brindado a la Corona.

préstamos y donativos a fines del siglo XVIII y principios del XIX”, Coloquio del proyecto Cambio Institucional, fiscalidad en el Mundo hispánico, 1750-1850, 17-19 de octubre, Toulouse, Francia

${ }^{81}$ AGNU, libro 477, fo 3 .

82 AGNU, libro 477, fo 6.

$8_{3}$ AGNU, libro 477, fo 10 vta y 11

84 DHA, tomo VII, p. 166. 
Los donativos, los préstamos o cualquier tipo de beneficio dados por los súbditos a la Corona, eran realizados buscando contraprestaciones económicas o institucionales.

La hegemonía institucional de la Junta de Gobierno del consulado fue interpretada en Montevideo como "tiranía" de Buenos Aires sobre Montevideo. Al contrario, en Potosí, parece un vínculo más equilibrado con preponderancia de los comerciantes locales. La cuestión del situado de comercio lo demostró: la Junta de Gobierno impulsó a los situadistas pero la influencia de las facciones internas y el poder de las juntas locales parecen ganar la pulseada. En Potosí, el poder corporativo de su diputación y su poder de negociación ante la corona era, sin duda, más significativo que el de Buenos Aires. ${ }^{85}$ Los comerciantes de la Montevideo observan que Buenos Aires "bebe su sangre, para engrosar su proprio cuerpo..." sólo el Rey puede, mediante la autorización de la creación del Consulado, "concluir la monstruosidad de humillarse a otro cuerpo inconexo, y distinto por naturaleza, y ubicación que no sólo le sirve de fomento, y conservación, sino que le oprime, y destruye cesando en su alimento." 86 Montevideo pagaba 1/5 de averías de lo recaudado en su aduana y era pagada mensualmente, esa exacción los ataba a Buenos Aires. Los comerciantes y hacendados solicitaban al rey su propio consulado para poder negociar con las autoridades monárquicas como interlocutores regionales. En este sentido el Consulado de Montevideo no distinguirá "al Hacendado del Comerciante" 87 como el de Buenos Aires. ${ }^{88}$ Este incluye a ambos intereses en un mismo cuerpo, con lo que desde el inicio formará un sector de poder.

85 Potosí contaba, desde el siglo XVII, con el Gremio de los azogueros. Ellos habrían sido el modelo de los gremios en Buenos Aires desde fines del siglo XVIII.

86 DHA, tomo VII, p. 166.

87 DHA, tomo VII, p. 166.

88 El consulado de Buenos Aires se integraba de comerciantes desde su creación en 1794 hasta la Real Cédula de incorporación de los hacendados en 1797, Fernando Jumar y Javier Kraselsky, "Las esferas del poder. Hacendados y comerciantes de Buenos Aires ante los cambios de la segunda mitad del siglo XVIII". Anuario del Instituto de Historia Argentina $N^{\circ} 7$, La Plata, Universidad Nacional de la Plata, Facultad de Humanidades y Ciencias de la Educación, p. 53. Estos dos cuerpos (el de comerciantes y el de hacendados) estaban enfrentados desde 1791. Guillermina del Valle Pavón, "Gestión del derecho de alcabalas y conflictos por la representación corporativa: la transformación de la normatividad electoral del Consulado de México en el siglo XVII" en Hausberger B. y Ibarra A. (ed.), Comercio y poder en América colonial. Los Consulados de comerciantes, siglos XVII-XIX, Madrid, Biblioteca Ibero-americana, 2003, p. 42; de la misma autora, "Apertura comercial del Imperio y reconstitución de facciones en el Consulado de México: el conflicto electoral de 1787". En G. del Valle Pavón, Mercaderes, comercio y Consulados de Nueva España en el siglo XVIII, México, Instituto Mora, 2003, p. 262 analiza las rivalidades en el consulado de México por la representación a mediados del siglo XVIII de los montañeses y vizcaínos. Este conflicto es resuelto por la Ordenanza de alternativa de 1742, por la cual ambas parcialidades designaban sus propios 
El 29 de noviembre de 1800 se produce otra Junta, en la que su apoderado Juan Ignacio Martínez convocó a los "comerciantes terrestres y marítimos residentes en esta Plaza, y los capitanes y Maestres de los buques que se hallen en este Puerto" y los "apoderados de los Hacendados Manuel Pérez, José Cardoso y Antonio Pereyra" 89 a tratar el tema era la "excesiva pension y gravamen que recientemente se ha impuesto al comercio por el Consulado de Buenos Aires" La Junta de Gobierno del consulado porteño impuso mayores derechos a la navegación de este puerto. ${ }^{\circ}$ Como respuesta a este gravamen, la junta en cuestión con 78 miembros manifestaba que aquel Consulado intentaba "abatir, hacer poco aprecio, y hechar por tierra al Cuerpo de este Comercio" como ya en otras ocasiones lo habría intentado "para cumplir el donativo de cien mil pesos que ofrecio a su Majestad". Los actores de Montevideo, lograron mediante sus Juntas "defenderse de la arbitrariedad con que aquel Consulado de Buenos Aires quiere subyugarle disponiendo libremente contribución a su giro" y pudieron obtener "protección" del virrey como ya se ha tratado. La junta designa como apoderado a José Milla de la Roca y Juan Francisco Martínez Méndez.

Estas relaciones basadas en el conflicto y la rivalidad regional eran la otra cara de la integración. Los puertos de Buenos Aires y Montevideo estaban en la práctica vinculados por sus actores económicos y sus intereses comerciales. Los vínculos eran tanto geográficos (formaban parte de una misma cuenca); Montevideo creció con Buenos Aires (tanto económicamente como en el origen de sus poblaciones); poseían nexos comerciales (las lanchas se utilizaban como medios de trasporte para las mercaderías) y contaban con lazos institucionales (la Contaduría general de Indias consideraba a las

candidatos alternándose en el gobierno de la corporación. Por dicha Ordenanza los dos grupos participaban en la misma proporción en la administración del cuerpo. Con esto, se ilustraba la intervención de la corona mediando en situaciones conflictivas entre los cuerpos, sean regionales y étnicos o socioprofesionales.

89 AGNU, libro 477, fo 17 vta, 18.

$9^{90}$ Los representantes del comercio manifiestan que "la exacción de un quatro por ciento á laextraccion y quatro reales por tonelada a cada Buque dealtura” AGNU, libro 477, $\mathrm{f}^{\circ} 18$. 
dos terminales portuarias como una sola). ${ }^{91}$ Las elites de la una y otra orilla se entrelazaban en los negocios. ${ }^{2}$ Muchos trabajos analizan la complementariedad de los puertos.93 A modo de ejemplo puede leerse el escrito de 29 de octubre de 1799, el cual ilustra cómo los "Dueños de las lanchas que hazen el trafico de este Rio", suplican al Rey "se digne a exonerar de toda contribución a las Lanchas costeras del trafico" 94 en la entrada al puerto de Montevideo. Hay muchos ejemplos sobre la asimilación de los dos puertos al mismo espacio. 95

\section{3-b) Formación del Consulado de Montevideo}

Tras la invasión napoleónica, la monarquía se desmorona en 1808. Como consecuencia de ello, tanto en Europa, como en América, comienzan a erigirse Juntas locales de gobierno que representaban los intereses de Fernando VII. ${ }^{96}$ Para la región del Río de la Plata, estos hechos se producirán con posterioridad a la ocupación inglesa de 1806 y 1807. No nos ocuparemos aquí del aspecto político de las invasiones ya que ha sido ampliamente debatido, 97 sino que nos referiremos a la importancia que tuvieron las juntas de comercio locales como ámbito de defensa corporativa y que promovieron la gestión del consulado de Montevideo.

Las dos ciudades se disputaban el control del comercio inglés que, desde el 2 de julio de 1808 con el armisticio hispano-británico y los cambios geopolíticos que implicó,

${ }^{91}$ A, Betancur, El puerto colonial de Montevideo. ...p.174

$92 \mathrm{~A}$, Betancur, El puerto colonial de Montevideo. ...p. 175.

93 F. Jumar, “La Región Río de la Plata...” pp. 123-157; N. Biangardi, Expansión territorial, producción ganadera....

94 Consulado, tomo IV, p. 314.

95 Los barcos enemigos que fueron atrapados por los corsarios del Consulado, eran vendidos en Montevideo y los fondos entregados a Buenos Aires, $\mathrm{f}^{\circ}$ 181, 241, 285 o las suspensiones del derecho de anclaje proveído por los dueños de lanchas en 26 de marzo de 1801 . AGN, IX 4-6-10, f ${ }^{\circ} 142$

96 Véase entre otros a José Carlos Chiaramonte, Ciudades, provincias y estados: Orígenes de la Nación Argentina (180o-1846), Buenos Aires: Emecé Biblioteca del Pensamiento Argentino, [1997] 2007, pp. 61-87; del mismo autor, Nación y Estado en Iberoamérica. El lenguaje político en tiempos de las independencias, Buenos Aires, Sudamericana, [1997] 2007, Marcela Ternavasio, Gobernar la Revolución. Poderes en disputa en el Río de la Plata, 1810-1816, Buenos Aires, Editorial Siglo XXI, 2007, pp. 77-126.

97 Remitimos a Tulio Halperín Donghi, Revolución y guerra. Formación de una elite dirigente en la Buenos Aires criolla, Buenos Aires, Siglo XXI, -1972- 1994; Klaus Gallo, Las invasiones inglesas. Buenos Aires: Eudeba, 2004. 
se convirtió en aliado de la corona en su lucha contra Napoleón. A este conflicto se sumaba el político con la formación en Montevideo de la Junta de Gobierno en oposición a la capital virreinal 98 y el surgimiento de la alternativa carlotista que incluía a los territorios de Brasil. 99

Así en esta coyuntura de cambio, en Montevideo se produjo una junta el 5 de marzo de 1810. En dicha Junta, compuesta de 77 miembros, trataron del pago de Nicolás Herrera, designado por este comercio en las corte de Madrid. Este apoderado, fue durante 4 años quien defendió los intereses del cuerpo de comercio ante las autoridades y que entre los cuales, la cuestión de la creación de su propio consulado habría sido central por lo que se comprometieron a brindar una suma de 20.000 ps. Sin embargo al no contar con esa cantidad, el cuerpo de comercio, lo recaudaría de la aduana por el dos por ciento de las introducciones "de frutos". ${ }^{100}$ Esto demuestra no sólo la importancia política del recurso a junta y la defensa corporativa de los espacios integrados a la monarquía, sino la capacidad de actuación de los mismos comerciantes residentes en Montevideo y corporados a través del gremio de recaudar gravámenes y de disponer de ellos. ${ }^{101}$

Una vez producidos los acontecimientos de mayo, la Junta Gubernativa del Río de la Plata en Buenos Aires desconoció al Consejo de Regencia y se negó a enviar Diputados a las Cortes en Cádiz. Al otro lado del río, en cambio se mantuvo la lealtad a las autoridades residentes en España. Con ello, las dos ciudades-puertos mantuvieron un conflicto desde 1810 hasta mediados de 1814, que culminó con la toma de Montevideo por el directorio de Alvear de Buenos Aires. ${ }^{102}$

98 Allí, se impuso la junta presidida por Francisco Javier Elío el 21 de septiembre de 1808 que juró fidelidad a la Junta Central Suprema del Reino el 14 de enero de 1809. Elío finalmente fue desplazado por Cisneros como nuevo Virrey, lo que provocó la disolución de la Junta de Montevideo. A. Bentancur, $E l$ puerto colonial de Montevideo...”; Ana Fraga, “La Junta de Montevideo de 1808” en Manuel Chust, 18o8, la eclosión juntera en el mundo hispano, México, FCE, 2008, pp. 252-253.

99 Joao Paulo Pimienta, Estado y Nación hacia el final de los imperios ibéricos. Río de la Plata y Brasil, 18o8-1828, Buenos Aires, Sudamericana, 2011, pp. 79-93

100 AGNU, libro 477, fo 33 vta

${ }^{101}$ Las juntas se convocaban para recaudar para obras de infraestructura como el muelle, el 23 de marzo de 1810 .

${ }_{102}$ Véase, A. Bentancur, El puerto colonial de Montevideo. Guerras y apertura comercial..., p.73. 
El cuerpo de comerciantes de Montevideo ya funcionaba como consulado de hecho. Este reclamo reaparece en la Junta general de "comerciantes, navieros y hacendados" del 24 de marzo de 1812 de la que participaron al menos 80 de ellos. En dicha Junta, los integrantes de ella designaron a como apoderado a don Manuel Gallego, Miguel Antonio Villardebo, Juan Torre de Lare. ${ }^{103}$ La junta trató sobre el comercio extranjero que ocasionaba "males incalculables, al estado, al comercio y principalmente a la marina mercante nacional". Los actores de Montevideo pidieron que "se prohíba absolutamente" tal comercio. Para eso solicitaban el "nombramiento de celadores" que vigilaran las salidas de barcos. La junta designó a Nicolás de Larrea y José Forrel para tal función. ${ }^{104}$

En esa fecha, los comerciantes, hacendados y navieros se reunieron en Junta y manifestaron la necesidad de crear un Consulado de comercio nombrando apoderados para llevar adelante todas las "gestiones y diligencias necesarias...." para crearlo. ${ }^{105} \mathrm{La}$ creación de éste estuvo estrechamente vinculada a razones políticas y habría sido, según mi opinión, el resultado de la lealtad de Montevideo a las autoridades legítimamente constituidas ante la invasión napoleónica y caída de Fernando VII.

En el memorial presentado, los actores de Montevideo sumaban a los reclamos de 1799 -el crecimiento de la plaza, la incomodidad del viaje al Consulado de Buenos Aires para realizar la apelación, etc. - la cuestión de la destrucción física del comercio y de los campos de pastoreo y de labranza. ${ }^{106}$ Pensaban que solo con la creación del Consulado les sería posible remediar la situación de los campos devastados por las guerras. Esta situación solo puede ser solucionada por "un cuerpo cuyo instituto sea únicamente la protección y fomento del comercio en todos sus ramos (...) de volberla al orden" ${ }^{107}$

Los comerciantes en Montevideo manifestaban la necesidad de poseer un Consulado propio, esa región poseía la comandancia general de Marina. Los actores locales se dirigían a los demás Consulados de Cádiz, Bilbao, Santander y Barcelona con el objetivo de establecer el suyo; los representantes de Montevideo decían que sino se "perderia

\footnotetext{
103 AGNU, libro 477, fo 48 vta

104 AGNU, libro 477, fo 49

105 MHN, tomo 442 reproducidas en el Apéndice por Capillas de Castellanos, Historia del Consulado de Comercio pp. 260-330.

${ }^{106} \mathrm{MHN}$, tomo $442 \mathrm{f}^{\circ} 7$ vta.

107 MHN, tomo 442 f $^{\circ} 51$ vta.
} 
quizas para siempre la América del Sur". ${ }^{108}$ Manifiestan su fidelidad ante las instituciones que representan a la Monarquía. Decían que

[...] es inneglable que á estos sacrificios, se debe haber podido hacer frente a las demas Provincias del Virreinato, que aspiran á su independencia ([como Buenos Aires, en cambio Montevideo]) en medio de tantos males y desdichas no se ha olvidado tampoco este fiel vecindario, y comercio de sus hermanos de Europa, que con las armas en la mano se sacrifican para que no seamos Esclavos [...].109

Para reclamar el Consulado, los representantes de Montevideo acudían a la recopilación de Leyes de Indias que decía que si bien no se podía fundar el Consulado sino era con la autorización del Rey, en Indias los Virreyes podían crearlo -según las glosas de estas mismas Leyes- dando cuenta al Rey para su aprobación. Los representantes observan que Montevideo es "la unica plaza fiel a su Rey y a la Nacion Española que ha quedado en todo el virreinato". ${ }^{110}$ Finalmente el señor Capitán General aprobó la instalación del Consulado: "en la Regencia de las Españas han aprobado el establecimiento de un Consulado enesta Plaza..." "111 y el 30 de mayo de 1812 se produjo la junta para elegir a sus miembros. La Junta general fue convocada por carteles, concurrieron 29 personas y eligieron a las autoridades. ${ }^{112}$

\section{Conclusión}

Sabido es que no existe una relación causal y directa entre los estados nacionales y los ex territorios de la corona hispánica. Los trabajos de José Carlos Chiaramonte sobre las revoluciones y la formación de soberanías autónomas iniciaron toda una tradición política renovada. ${ }^{113}$ A esto se le suman las vertientes económicas sobre los circuitos y los

\footnotetext{
${ }^{108} \mathrm{MHN}$, tomo $442 \mathrm{f}^{\circ} 14$.

$109 \mathrm{MHN}$, tomo $442 \mathrm{f}^{\circ} 51$.

$110 \mathrm{MHN}$, tomo 442, fo 49 vta.

${ }^{111}$ El 22 de mayo de 1812 se permite su creación, hasta la autorización definitiva del Rey. MHN, tomo $442, \mathrm{f}^{\circ} 61$.

${ }_{112} \mathrm{MHN}$, tomo 442, $\mathrm{f}^{\circ} 67$

113 Véase J. C. Chiaramonte, Ciudades, provincias y estados, pp. 61-86; del mismo autor, Nación y Estado en Iberoamérica, pp. 27-57; J. P. Pimienta, Estado y Nación...”, pp. 31-72.
} 
mercados interiores entre los siglos XVII-XIX que abordan la formación de los estados. ${ }^{114}$ De este modo resulta anacrónico observar las naciones y los estados preexistentes a la disolución monárquica. Sobre esta senda se puso de manifiesto la cuestión política e institucional y las tensiones y conflictos sobre los espacios a fines del siglo XVIII.

Estas regiones tuvieron desarrollos económicos diferentes, como así también la importancia y las características de sus comunidades mercantiles. La corporación de comerciantes en Buenos Aires tuvo un significativo crecimiento durante el siglo XVIII. Ya antes de la creación del consulado, desde el año 1748 se desarrollaban las juntas de comercio locales. Estas reciben un importante estímulo en el año 1752 con la fundación de la Diputación de comercio del Consulado de Lima. Luego de disuelta esta en 1756 las juntas de comercio adquieren importancia corporativa para representar los intereses mercantiles transformándose en ámbito de defensa colectivo de tales intereses.

En 1779, las juntas informales dan paso a las Juntas formales, dichas organizaciones contaban con apoderados permanentes, estructuras contables y modalidades específicas de funcionamiento. Es decir, actuaban como un consulado de "hecho". En esta etapa se producen dos de las innovaciones institucionales centrales: se crea el virreinato del Río de la Plata y se sanciona el Reglamento de Libre comercio. En 1794 se institucionaliza el consulado de Buenos Aires y posteriormente se crean las Diputaciones regionales. Estas transformaciones institucionales se producen por un conflicto entre los comerciantes que convocaban a las juntas de comercio y los hacendados de Buenos Aires, por el monopolio de la comercialización de los cueros desde 1790. Dicho conflicto motivó a sus actores a instituir las juntas en el consulado. Además, y como lo hemos señalado, los comerciantes eran los únicos que podían brindar sus ingresos monetarios a la corona en tiempos de guerra contra la Francia revolucionaria.

El consulado porteño tuvo una serie de Diputaciones regionales. En este trabajo abordamos dos como Potosí y Montevideo. Para analizar las relaciones que mantuvieron con la Junta de Gobierno, nos centramos en tres cuestiones. Primero en la capacidad

\footnotetext{
114 Véase C. S. Assadourian, El Sistema de la Economía Colonial... pp. 109-134; Z. Moutoukias, Contrabando y control colonial ..., pp. 15-69; M. A. Irigoin y R. Schmit, (Ed.) La desintegración de la economía colonial...; C. S. Assadourian y S. Palomeque, "Los circuitos mercantiles del "interior argentino" y sus transformaciones durante la Guerra de la Independencia (1810-1825)", pp. 49-70; Viviana, Conti, "Una periferia del espacio mercantil andino. El Norte argentino en el siglo XIX", Avances de Investigación, Salta, 1989; V. Conti y G. Sica, “Arrieros andinos de la Colonia....” pp. 1-19; F. Jumar, "La Región Río de la Plata ..., pp. 123-157.
} 
de gestión de las juntas de comercio. Tanto en Potosí como en Montevideo, los comerciantes locales utilizaron esos ámbitos políticos como defensa para sus intereses corporativos. Así, los comerciantes planifican y llevan adelante sus estrategias para conseguir beneficios o ventajas grupales. A cambio otorgan ingresos de toda la comunidad y la conservación del control político de la corona sobre el territorio. Los donativos y préstamos en el caso de Montevideo o la entrega de los caudales del comercio en Potosí, además de una serie de impuestos que recaían sobre la comunidad son muestra de ello.

En segundo lugar y estrechamente vinculado al anterior, encontramos el control político e institucional no implicó el control económico real sobre los espacios regionales. La Junta de Gobierno del consulado de Buenos Aires poseyó el dominio sobre la designación de los diputados y desde 1804 sobre los situadistas o recaudadores del comercio de Potosí. Esto trajo profundas rivalidades y antagonismos entre los comerciantes agrupados en juntas locales y el núcleo porteño. En el caso de Potosí, las disputas entre las facciones de comerciantes fueron constantes, la junta de Gobierno del consulado de Buenos Aires cumplió el papel de árbitro para pacificar los conflictos. En este sentido en esta Diputación se suspendieron las juntas de comercio que no cumplían con el requisito de ser convocadas con temas previamente dados y autorizados desde la Diputación.

En tercer lugar las dos regiones políticas y económicas fueron, como todas las diputaciones del Alto Perú y Paraguay, las que generarían espacios autónomos en el siglo XIX de la capital del ex virreinato del Río de la Plata. Eso es, que desechando las visiones "nacionales" y basándonos en los territorios jurisdiccionales de la monarquía compuesta, la intención fue profundizar sobre los nexos políticos entre los polos de crecimiento de un espacio determinado. La Junta de Gobierno del consulado de Buenos Aires, dominó políticamente todo el espacio del virreinato fortaleciendo su control económico y mercantil con estructuras políticas como las Diputaciones. Los conflictos con Montevideo, no preanuncian ni explican la separación de dos estados diferentes pero influyen en la formación de dos ciudades-puertos con intereses circunstancialmente enfrentados, con estrategias y prácticas políticas como las Juntas de comercio.

Además, estudiamos la conformación, a partir de las Juntas de comercio de las iniciativas de creación de nuevos consulados como el de Montevideo. Para Buenos Aires el consulado, era una institución por la cual las elites de comerciantes se transformaron en interlocutores de la corona. En este sentido era el nexo entre la corona y los espacios interiores. Las elites de Montevideo pretendían serlo, y la creación de su propio consu- 
lado era central para ello. Este fue el resultado de la lealtad de esta ciudad a las instituciones creadas con posterioridad al derrumbe de la corona y el rechazo a adherirse al proceso revolucionario desencadenado en Buenos Aires. Las elites de comerciantes y hacendados podrían ahora contar con los beneficios institucionales de poseer un consulado propio - capacidad política, defensa corporativa, autonomía jurídica, etc- asegurando la fidelidad de los territorios a España. La razón por la que se crea el Consulado de Montevideo, en mi opinión, debe buscarse más en la relación de los espacios locales con la monarquía, que en la relación conflictiva entre Buenos Aires como antigua capital del virreinato. Los actores de Montevideo establecieron su Consulado en 1812, después de haberlo solicitado desde 1793. En Potosí, si bien es claro que esto no se fomentó nunca. Quizás podemos abordar como hipótesis que el Consulado no fue necesario porque esta villa, integrada a la Audiencia de Charcas, no tuvo necesidad de defensa corporativa, debido a su riqueza, no necesitaban de esta institución para transformarse en interlocutores de la corona.

En Buenos Aires, el Consulado de Comercio mantuvo sus funciones de gremio con su Junta de gobierno y tribunal mercantil hasta 1821. En ese año muchas de sus facultades fueron disueltas y muchas de sus potestades fueron trasladadas a otras instituciones. La disolución definitiva de lo que quedaba de esta institución fue en 1862, año en que el gobierno de Bartolomé Mitre, unificó la administración de justicia del país quedando transformado en juzgado de comercio letrado. Es decir en la etapa de formación del Estado argentino.

En este trabajo intentamos demostrar que, mediante su consulado y su Junta de Gobierno, Buenos Aires contó con un control político-institucional sobre las diputaciones de Potosí y Montevideo, pero que éstas mediante sus recursos colectivos de convocatoria a juntas de comercio, podían proteger sus intereses económicos y políticos. El trabajo intentó brindar elementos para interpretar la desintegración territorial debido al derrumbe monárquico y la emergencia de las soberanías políticas autónomas. Mediante el, podemos profundizar hipótesis o elementos que expliquen si la actual fisonomía del estado nacional argentino y posiblemente la actual configuración de los estados hispanoamericanos está relacionada a las redes mercantiles y a las redes consulares y de ser así, como ha influido en su formación. 


\section{Bibliografía}

\section{Fuentes primarias:}

Actas: Archivo General de la Nación. Consulado de Buenos Aires. Antecedentes-ActasDocumentos. Buenos Aires: Kraft, Tomo I, 1936

AECBA: Archivo General de la Nación, Acuerdos del extinguido Cabildo de Buenos Aires. Buenos Aires, Serie III, tomos III-IX.

AGN: Archivo General de la Nación (Argentina).

DHA: Documentos para la Historia Argentina. Facultad de Filosofía y Letras, 1913-1919.

AGNU: Archivo General de la Nación. Montevideo

MHN, Museo Histórico Nacional. Montevideo

\section{Fuentes secundarias:}

Aguirre, Luis "Desinteligencias en los negocios: Redes sociales y circuitos comerciales durante la Cisplatina en Montevideo", Ad Fontes! Vol. 1, No. 1, 2014

Aguirre, Luis "Los consulados de comerciantes en la Independencia de Hispanoamérica, el caso del Consulado de Montevideo: 1794-1838”. México: Tesis para obtener el grado de Maestro en Economía, UNAM, 2014.

Aillón Soria, Esther Vida, pasión y negocios: el propietario de la viña San Pedro Mártir, Indalecio González de Socasa (1755-1820), Sucre, Fundación Cultural del Banco Central de Bolivia, Archivo y Biblioteca Nacionales de Bolivia, 2009.

Ana Fraga, "La Junta de Montevideo de 1808" en Manuel Chust, 1808, la eclosión juntera en el mundo hispano, México, FCE, 2008, pp. 252-253.

Assadourian Carlos Sempat y Silvia Palomeque (2010). "Los circuitos mercantiles del "interior argentino" y sus trasformaciones durante la Guerra de la independencia (1810-1825)”. En: Bandieri, Susana (compiladora) La Historia económica y los procesos de independencia en la América Hispánica. Buenos Aires: Prometeo, pp. 49-71.

Assadourian, Carlos Sempat, El Sistema de la Economía Colonial. El mercado interior, regiones y espacio económico, México, Nueva Imagen, 1983.

Barba, Enrique M., Don Pedro de Cevallos, Madrid, Instituto de Cooperación Iberoamericana -1937- 1988. 
Bentancur, Arturo Ariel, El puerto colonial de Montevideo. Guerras y apertura comercial: tres lustros de crecimiento económico (1791-1806), Universidad de la Republica, Departamento de Publicaciones, 1997.

Biangardi, Nicolás Expansión territorial, producción ganadera y relaciones de poder en la región Rio de la Plata. Montevideo y Maldonado a fines del siglo XVIII, Tesis de Doctorado, Universidad Nacional de La Plata, 2015, inédita

Capillas de Castellanos, Aurora, Historia del Consulado de Comercio de Montevideo (1795-1815), Separata de: Revista Histórica (Museo Histórico Nacional), XXXII, 1962

Celaya Nández, Yovana, "Los diputados de la Junta de comercio de Puebla: estrategias de negociación y representación de intereses en el siglo XVIII”. Congreso latinoamericano de Historia Económica -CLADHE III-XXIII Jornadas de Historia Económica Argentina -AAHE-Universidad Nacional del Comahue, San Carlos de Bariloche (República Argentina), 2012

Chiaramonte, José Carlos Ciudades, provincias y estados: Orígenes de la Nación Argentina (180o-1846), Buenos Aires: Emecé Biblioteca del Pensamiento Argentino, [1997] 2007

Chiaramonte, José Carlos, Nación y Estado en Iberoamérica. El lenguaje político en tiempos de las independencia,. Buenos Aires, Sudamericana, 2004.

Conrad R. y Gallego J. A., Las monarquías del Antiguo Régimen, ¿monarquías compuestas? Madrid, Editorial Complutense, 1996.

Conti, Viviana "Una periferia del espacio mercantil andino. El Norte argentino en el siglo XIX", Avances de Investigación, Salta, 1989.

Conti, Viviana y Gabriela Sica (2011) Arrieros andinos de la colonia a la independencia" en Nuevo Mundo Mundos Nuevos, Debates 2011 (en Linea)

Cruz Barney, Oscar El régimen jurídico de los consulados de comercio indianos: 17841795, México, Instituto de Investigaciones Jurídicas de la Universidad Nacional Autónoma de México, 2001

Cruz Barney, Oscar, "Las diputaciones foráneas del consulado de México: 1807 y 1816" en Ibarra Antonio y Guillermina del Valle Pavón (coord.) Redes sociales e Instituciones comerciales en el imperio español, siglos XVIII a XIX, México, Instituto Mora, 2007, pp. 295-325.

Elliott, J. “A Europe of Composite Morarchies”, Past and Present, 137, 1992, 48-71.

Gallo, Klaus, Las invasiones inglesas, Buenos Aires, Eudeba, 2004. 
Halperin Donghi, Tulio, Revolución y guerra. Formación de una elite dirigente en la Buenos Aires criolla, Buenos Aires, Siglo XXI, -1972- 1994.

Ibarra, Antonio, "Mercado global, economías regionales y corporaciones comerciales: los consulados de Guadalajara y Buenos Aires, 1795-1810" Revista Mexicana, año $\mathrm{n}^{\mathrm{O}}$ 248, 2012, pp. 1419-1455.

Irigoin, Alejandra y Schmit, Roberto (Ed.) La desintegración de la economía colonial, Editorial Biblos, Buenos Aires, 2003.

Jumar Fernando y Javier Kraselsky. "Las esferas del poder. Hacendados y comerciantes de Buenos Aires ante los cambios de la segunda mitad del siglo XVIII." Anuario del Instituto de Historia Argentina $N^{\circ} 7$, La Plata: Universidad nacional de la Plata, Facultad de Humanidades y Ciencias de la Educación, 2007, pp. 31-57.

Jumar, Fernando "La Región Río de la Plata y su complejo durante el Antiguo Régimen". En Fradkin, Raúl, Historia de la Provincia de Buenos Aires. De la conquista a la crisis de 1820, Buenos Aires, Editorial Edhasa, 2012, pp. 123-157

Jumar, Fernando, Le commerce atlantique au Río de la Plata, 1680-1778, Lille: Presses Universitaires du Septentrión, 2 vols., 2002

Kraselsky, Javier "El consulado de comercio de Buenos Aires y sus redes locales. El caso de la Diputación de Potosí a fines del siglo XVIII y comienzos del XIX”, presentado en el Congreso Latinoamericano de Historia Económica (CLADHE IV), Universidad de Bogotá Jorge Tadeo Lozano. Bogotá, Colombia, 23-25 de julio de 2014.

Kraselsky, Javier "Los comerciantes rioplatenses y sus estrategias de negociación corporativa. Las Juntas de comercio, 1779-1794”, Ibarra A. y Valle Pavón del G.(coor) Redes sociales e Instituciones consulares en el Imperio Español, siglos XVII a XIX, , Instituto de Investigaciones Dr. José María Luís Mora y la Facultad de Economía de la Universidad Nacional Autónoma de México, 2007, pp. 249278

Kraselsky, Javier, "Las estrategias de los actores del Río de la Plata: las Juntas y el Consulado de comercio de Buenos Aires a fines del Antiguo Régimen (1748-1809)" Universidad Nacional de La Plata, tesis de Doctorado, inédita, 2010.

Kraselsky, Javier, "Las Juntas de comercio y el Consulado de Buenos Aires y sus relaciones con la Corona: los préstamos y donativos a fines del siglo XVIII y principios del XIX" Coloquio del proyecto "Cambio Institucional, fiscalidad en el Mundo hispánico, 1750-1850" 17-19 de octubre de 2011. Toulouse, Francia

Kraselsky, Javier, "Las relaciones entre los actores del Río de la Plata: el Consulado de comercio de Buenos Aires y su Diputación en Montevideo (1794-1812)” XII Jor- 
nadas Interescuelas-Departamentos de Historia, Universidad Nacional del Comahue, Facultad de Humanidades, Centro Regional Universitario Bariloche, 2009.

Mariluz Urquijo, José María, "El Diputado del Consulado de Lima en Buenos Aires" En: Academia Nacional de la Historia. Memoria del Cuarto Congreso Venezolano de Historia, tomo II, Caracas, 1983, pp. 331-355.

Mazzeo, Cristina, Gremios mercantiles en las guerras de la independencia. Perú y México en la transición de la colonia a la República, 1740-1840, Lima, Instituto de Estudios Peruanos/Banco Central de Reserva del Perú, 2012.

Moutoukias, Zacarías, "Las formas complejas de la Acción política: Justicia corporativa, faccionalismo y redes sociales (Buenos Aires, 1750-1760) En: Jahrbuch Fur Geschichte Lateinnamerickas, Colonia, 2002.

Moutoukias, Zacarías, Contrabando y control colonial en el siglo XVII, Buenos Aires, Centro Editor de América Latina, 1988.

Pimienta, Joao Paulo Estado y Nación hacia el final de los imperios ibéricos. Río de la Plata y Brasil, 1808-1828, Buenos Aires, Sudamericana, 2011, pp. 79-93

Pivel Devoto, Juan E., Raíces coloniales de la Revolución de 1811. Montevideo: Ed. Medina, 1957.

Saguier, Eduardo "La conducción de los caudales de oro y de plata como mecanismo de corrupción. El caso del situado asignado a Buenos Aires por las Cajas Reales de Potosí en el Siglo XVIII", Historia, vol 24, 1989, pp. 287-317

Silva, Hernán Asdrúbal, El comercio entre España y el Río de la Plata (1778-181o). Madrid: Banco de España- Servicio de Estudios- estudios de Historia Económica, $\mathrm{n}^{\circ} 26,1993$.

Ternavasio, Marcela, Gobernar la Revolución. Poderes en disputa en el Río de la Plata, 1810-1816, Buenos Aires, Editorial Siglo XXI, 2007.

Tjarks, Germán, "Potosí y los situados del comercio", Boletín del Instituto Ravignani, año IV, tomo IV no 8, 1960.

Tjarks, Germán, El Consulado de Buenos Aires y sus proyecciones en la Historia del Río de la Plata, Buenos Aires, Instituto de Historia Argentina "Doctor Emilio Ravignani”, 1962

Torres Sánchez, Rafael El precio de la guerra. El Estado fiscal-militar de Carlos III (1779-1783), Marcial Pons. Historia, 2013, pp. 13-129

Valle Pavón, Guillermina del "Gestión del derecho de alcabalas y conflictos por la representación corporativa: la transformación de la normatividad electoral del 
Consulado de México en el siglo XVII”. En Hausberger B. y Ibarra A. Comercio y poder en América colonial. Los Consulados de comerciantes, siglos XVII-XIX, Madrid, Biblioteca Ibero-americana., 2003.

Valle Pavón, Guillermina del, "Apertura comercial del Imperio y reconstitución de facciones en el Consulado de México: el conflicto electoral de 1787", Valle Pavón del, Guillermina, Mercaderes, comercio y Consulados de Nueva España en el siglo XVIII, coordinado por México, Instituto Mora. 2003. 